\title{
PROPOSTA DE ABORDAGEM TEMÁTICA COM ENFOQUE CTS NO ENSINO DE FÍSICA: PRODUÇÃO DE ENERGIA ELÉTRICA
}

\author{
CAMPOS, Lidiane Benites ${ }^{1}$ \\ CRUZ, Frederico Alan de Oliveira ${ }^{22}$ \\ PORTO, Claudio Maia ${ }^{3}$
}

\section{RESUMO}

Este trabalho apresenta uma proposta didática para o ensino de Física segundo a abordagem CTS. Seguindo a filosofia de contextualização inerente à concepção, construímos uma proposta voltada para a comunidade escolar do município de Angra dos Reis, explorando, para tanto, o tema da produção de energia elétrica, em suas várias modalidades, mas dando especial ênfase à energia nuclear, tendo em vista a localização na região de três usinas nucleares. Mostramos que essa escolha é absolutamente conforme as diretrizes da corrente CTS, constituindo tema de enorme significação para o público a que se destina a proposta. Apresentamos, então, com detalhes, a proposta de uma sequência didática, dividida em quatorze aulas, sugerindo um conjunto de atividades, adequadas à concepção em tela, a serem realizadas ao longo do período.

Palavras-Chave: Ensino de Ciências - Ensino de Física - Educação CTS - Produção de energia.

\section{ABSTRACT \\ In this work we present a didactic proposal for a Physics teaching based on STS approach. According to the contextualizing framework proper to that conception, we constructed a pro- posal turned towards the scholar community of the municipality of Angra dos Reis, RJ, ex- ploring, for such, the issue of eletric energy production in its various modes, but giving spe- cial emphasis to the nuclear one, given the localization at the region of three nuclear plants. We show that this choice of issue is in complete accordance with STS' guidelines, this issue being of enourmous significance to the public this proposal is turned to. We then present thoroughly the proposal of a didactic sequence divided in fourteen classes, suggesting a set of activities congenial to the conception in consideration, to be executed along the period. \\ KeYwORDS: Science Teaching - Physics Teaching - STS Education - Energy production. \\ 1 Mestranda do Programa de Pós-graduação em Educação, Ciências e Matemática da Universidade Federal Rural do Rio de Janeiro. Email: lidiane_benites@hotmail.com \\ 2 Departamento de Física da Universidade Federal Rural do Rio de Janeiro. Email: frederico@ufrrj.br \\ 3 Departamento de Física da Universidade Federal Rural do Rio de Janeiro. Email: claudio@ufrrj.br}




\section{INTRODUÇÃO}

As relações recíprocas entre a ciência, a tecnologia e os diversos aspectos da vida em sociedade são profundas; não só os desenvolvimentos científicos e tecnológicos produzem impactos nas diversas dimensões da dinâmica social, o que é uma constatação imediata e evidente, mas também é importante compreendermos as influências que fatores sociais e culturais têm sobre as transformações de pensamento subjacentes às inovações da ciência e seus desdobramentos em termos de tecnologia, sem descartar ainda os estímulos e condicionantes mais diretos que políticas públicas exercem sobre a evolução de determinados desenvolvimentos técnicos (MCKAVANAGH \& MAHER, 1982 apud SANTOS \& MORTIMER, 2002; MAZZUCATO, 2014). Tais relações se tornaram ainda mais determinantes à medida que a penetração das aplicações científicas e tecnológicas nos vários planos da vida social foi se acentuando de forma acelerada ao longo dos dois últimos séculos.

Se, de início, os benefícios do progresso científico produziram uma era de otimismo em relação às perspectivas das novas sociedades industriais-tecnológicas, essa avaliação foi se tornando gradualmente mais crítica, à proporção que se evidenciaram efeitos ambientalmente danosos ou moralmente questionáveis dos produtos da ciência e da tecnologia: os acidentes nucleares, o fantasma de uma guerra nuclear, a manipulação genética de espécimes vegetais e animais e os desequilíbrios no meio ambiente contribuíram fortemente para a formação de uma consciência crítica a respeito do progresso material e tecnológico.

Após a Segunda Guerra Mundial, essa perspectiva crítica deu origem a um movimento político-cultural representado pela sigla CTS (em inglês STS), correspondente a "Ciência, tecnologia e sociedade", cujos objetivos eram justamente enfatizar e analisar as mencionadas inter- relações entre esses agentes, além de induzir a participação coletiva da sociedade em escolhas que a todos afetavam, buscando proporcionar ao conjunto dos cidadãos os meios intelectuais necessários a esta participação.

Podemos dizer que, ao buscar proporcionar aos cidadãos a consciência necessária para a realização das escolhas de toda ordem que os afetam, este movimento se contrapõe diretamente às concepções falaciosas acerca da assepsia de uma racionalidade de caráter unicamente técnico a decidir sobre os destinos de toda a comunidade. Contra essas concepções já nos adverte Habermas, ecoando, em sua obra "Técnica e Ciência como Ideologia", a crítica de Marcuse:

"Marcuse está convencido de que naquilo que Weber chamou de 'racionalização' não se impõe uma 'racionalidade' enquanto tal, mas sim uma forma de dominação política oculta imposta em seu nome. Como a racionalidade desse tipo se refere tão somente à escolha correta entre estratégias, ao emprego apropriado da tecnologia e à instauração adequada de sistemas (para fins estabelecidos em situações dadas), ela subtrai à reflexão e à reconstrução racional o contexto dos interesses sociais mais amplos contidos nas estratégias eleitas, nas tecnologias empregadas e nos sistemas instituídos." (HABERMAS, 2014, p.76).

Todavia, a necessidade de participação coletiva nos processos decisórios requer uma educação científica habilitante para 0 exercício desta cidadania plena. Portanto, o movimento CTS se refletiu em uma vertente pedagógica, centrada na preocupação com a formação de cidadãos dotados de instrumentos intelectuais necessários à compreensão dos elementos mais gerais envolvidos nas questões científicas e 
e-Mosaicos - Revista Multidisciplinar de Ensino, Pesquisa, Extensão e Cultura do Instituto de Aplicação Fernando Rodrigues da Silveira (CAp-UERJ)

tecnológicas, de forma a torná-los agentes decisórios conscientes em relação à evolução de suas sociedades. Na verdade, transferida para a realidade da educação moderna, sobretudo em países com um historicamente grande déficit educacional, como o Brasil, essa vertente aponta também para outro elemento estratégico na luta pela reversão de um processo de aprendizagem muitas vezes ineficaz, qual seja, conferir ao estudo das ciências, frequentemente conduzido de maneira bastante abstrata, um caráter bem mais significativo, ao mostrar como esses conhecimentos científicos estão presentes e são influentes na realidade mais concreta do estudante.

Esses dois elementos se reúnem em uma abordagem CTS: a significância dos conhecimentos, uma vez identificados e relacionados à vivência mais próxima dos alunos e, deste modo, estimulando os processos de aprendizagem; a capacitação para a compreensão das implicações envolvidas em escolhas que, embora de fundo técnico, têm um impacto decisivo sobre o modo e a qualidade de vida dos indivíduos e das comunidades e, por conseguinte, não podem ser delegadas a uma suposta autoridade tecnocrática racionalmente isenta em suas decisões, mas sim devem ser exercidas pelos membros das comunidades por elas impactadas (SANTOS \& MORTIMER, 2002). Dito de outra maneira, o pleno exercício da cidadania exige a conscientização inclusive minimamente técnica dos seres humanos vivendo em comunidade.

Neste contexto, o movimento CTS se consolidou em sua forma educativa tendo como primeiro objetivo a alfabetização científica (CHASSOT, 2000) e tecnológica da sociedade (FOUREZ, 1995; SANTOS \& SCHENETZLER, 1997; SANTOS \& MORTIMER, 2001; SANTOS 2007), 0 que significa oferecer à sociedade os meios para "ler, compreender e expressar opiniões sobre ciência e tecnologia" (KRASILCHIK \& MARANDINO, 2004, p. 26). Somente uma sociedade esclarecida e capacitada a compreender o desenvolvimento da ciência e da tecnologia, bem como suas múltiplas implicações nos planos ético, político, econômico e cultural, avaliando as consequências sociais e ambientais de determinada técnica a curto, médio e longo prazo, em contraposição aos os benefícios que irá proporcionar, é capaz de participar com plena consciência das decisões a respeito de suas organizações e seus destinos. Nas palavras de Fourez:

\begin{abstract}
"Para ser um indivíduo autônomo e um cidadão participativo em uma sociedade altamente tecnizada deve-se ser cientifica e tecnologicamente "alfabetizado". Sem certas representações que permitem apreender o que está em jogo no discurso dos especialistas, as pessoas arriscam-se a se verem tão indefesas quanto os analfabetos em uma sociedade onde reina a escrita." (FOUREZ, 1995, p.222).
\end{abstract}

Os currículos CTS começaram a ser desenvolvidos com este propósito, promover a alfabetização em ciência e tecnologia de modo a capacitar o cidadão para participar democraticamente dos processos decisórios e promover a ação cidadã encaminhada para a solução dos desafios que se lhe apresentam (WAKS, 1990). Para isto a educação com enfoque CTS deveria desenvolver habilidades como:

"...a autoestima, comunicação escrita e oral, pensamento lógico e racional para solucionar problemas, tomada de decisão, aprendizado colaborativo/cooperativo, responsabilidade social, exercício da cidadania, flexibilidade cognitiva e interesse em atuar em questões sociais" (HOFSTEIN et al apud SANTOS E MORTIMER, 2001, p.96). 
Na medida em que busca valorizar a participação coletiva no processo decisório, a educação científica para a cidadania deve se pautar por outra lógica que não seja a de fornecer para os problemas em análise soluções prontas, oriundas de autoridades inquestionáveis, nem tampouco o de impor a validade de modelos tidos como certos, mas sim a de fornecer subsídios, produzir questionamentos e apontar possíveis critérios para uma escolha, cabendo a cada um, mediante debates coletivos, decidir o que é ou não aceitável. Nesse sentido, o processo desenvolvido por uma educação científica com enfoque CTS se diferencia fundamentalmente do ensino tradicional de ciências: afinal, enquanto nesse último busca-se apresentar a resolução de um problema como um resultado único e exato, previamente definido e esperado, na abordagem CTS os problemas, reais e concretos, não apresentam uma solução única, mas oferecem alternativas múltiplas, cuja escolha tem um traço subjetivo inalienável.

Um elemento fundamental dessa concepção pedagógica focalizada na alfabetização científica com vistas à formação de uma consciência decisória, tendo como diretriz estratégica a atribuição de um caráter significativo a esses conhecimentos, consiste na abordagem contextualizada dos conhecimentos da ciência, principalmente através do uso de temas extremamente relevantes para as comunidades envolvidas (DELIZOICOV et al, 2002; SANTOS, 2008). Os temas abordados em uma educação com enfoque CTS devem ter um significado real para os alunos; não devem simular questões distantes da vida dos alunos e sim reproduzir as suas realidades (RANSEY, 1993). Além disso, devem ser temas científicos ou tecnológicos e potencialmente problemáticos do ponto de vista social (RUBBA, 1991; RANSEY, 1993; SANTOS, 2002).

Segundo Ransey (RANSEY, 1993), um tema pertinente a uma abordagem educacional CTS pode ser identificado a partir de três critérios básicos: deve abordar um problema de natureza controvertida; deve ter um significado social; e deve ser relativo à ciência e à tecnologia.

O primeiro critério significa que devem existir opiniões diversas sobre o tema, de modo que este incentive um debate, envolvendo um diálogo entre diferentes ideias e uma discussão sobre possibilidades diversas de solução; já o segundo critério estabelece que o tema deve ser, de fato, um problema que atinja a coletividade na qual o estudante se insere, de modo que sua solução melhore as condições de vida, não só dele, mas de uma parcela significativa da sociedade à qual ele pertence. Nessas condições, a temática assumirá para esse estudante todo o seu caráter significativo, convidando-o afetivamente para o esforço intelectual de solução dos problemas apresentados (RUBBA, 1991; RANSEY, 1993; PATRONIS et al, 1999). Por fim, o terceiro critério restringe, obviamente, a variedade de problemas sociais pertinentes a uma educação científica àqueles que têm um caráter estruturalmente científico ou tecnológico.

Por conseguinte, a escolha dos temas a serem tratados constitui uma etapa metodológica importante para qualquer proposta educacional CTS. Na proposta aqui apresentada, este fator, atendendo aos quesitos apontados por Ransey, certamente representou uma preocupação primordial em sua elaboração.

\section{Metodologia}

O trabalho aqui apresentado tem como foco a apresentação de uma proposta de abordagem CTS dentro de uma escola pública da rede estadual de ensino, localizada no município de Angra dos Reis, RJ. Esse município está localizado a 157 da capital fluminense e tem grande importância no sistema elétrico brasileiro, por sediar as únicas usinas nucleares em fun- 
cionamento no Brasil: "Angra 1", em operação desde meados da década de 80 e que possui potência de 640 megawatts, e "Angra 2", que começou a operar no início dos anos dois mil e cuja potência é de 1.350 megawatts.

\subsection{ESCOLHA DO TEMA}

A abordagem CTS é fundamentalmente uma abordagem temática. Assim, uma proposta com enfoque CTS deve ser construída a partir de um tema articulável com a disciplina pela qual o professor é responsável. Portanto, a primeira etapa do trabalho consiste na escolha desse tema central e na definição dos assuntos a serem priorizados para a elaboração de uma proposta de abordagem temática. No caso específico da física, que é uma área muito abrangente e possui muitos temas que atendem aos objetivos da abordagem CTS, é preciso determinar alguns critérios para esta escolha.

Essa avaliação nem sempre é simples; alguns autores, embora concordem que a abordagem CTS deva ser temática, possuem opiniões divergentes sobre os critérios para a definição dos temas. Merrifield (1991) defende que eles devam ser globais e não apenas de importância local ou nacional. Nesta perspectiva, alguns temas são sugeridos: ambientais; saúde e população; questões econômicas; transporte e comunicação; alimentos e fome; energia; questões militares.

Por sua vez, Paulo Freire (1987), embora não se refira especificamente à educação em ciências, acredita uma educação libertadora deve se apoiar na interação do indivíduo com suas condições existenciais (FREIRE, 1996). Assim, para ele, os temas devem se originar na situação presente e concreta dos alunos, para depois evoluir para a análise de problemas regionais e nacionais.
Outros autores procuraram identificar os temas mais frequentes em abordagens CTS (SANTOS, 2002), como Towse (1986), cujo elenco temático em grande parte coincide com a listagem promovida por Merryfield (Fig. 01).

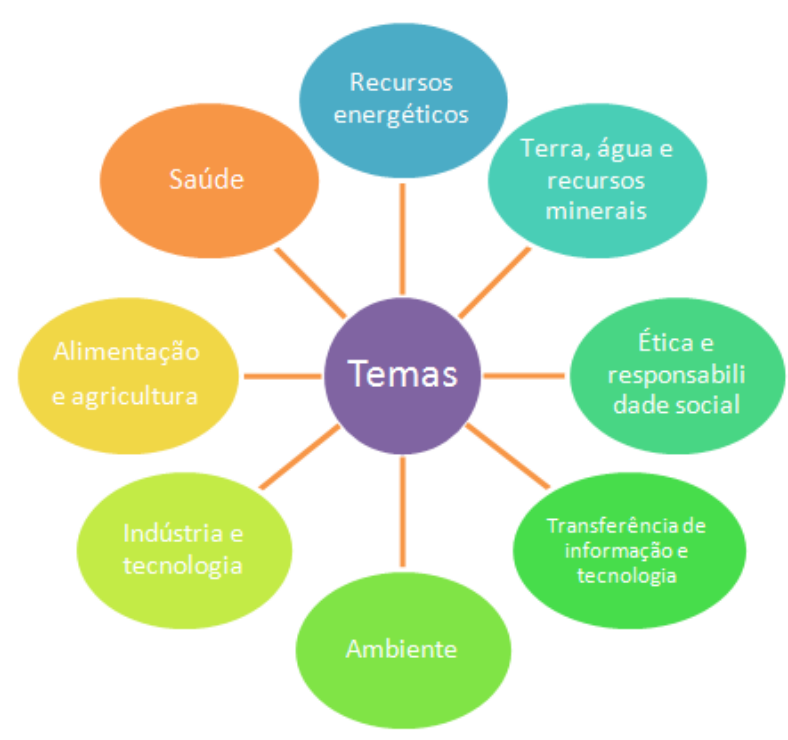

Fig 01: Agrupamento de temas proposto por Merryfield.

Os pesquisadores Bybee e Mau (1986) identificaram um elenco de temas centrais semelhantes a esses, porém mais específicos, enquanto Santos (2002) sugere alguns temas para abordagem no contexto brasileiro e aponta assuntos relevantes a serem tratados em cada tema, como, por exemplo, exploração mineral e desenvolvimento científico, tecnológico e social; ocupação humana e poluição ambiental; destino do lixo e impactos sobre o ambiente; produção de alimentos, fome populacional e alimentos transgênicos; e preservação ambiental, políticas de meio ambiente e desmatamento (Fig. 02). 


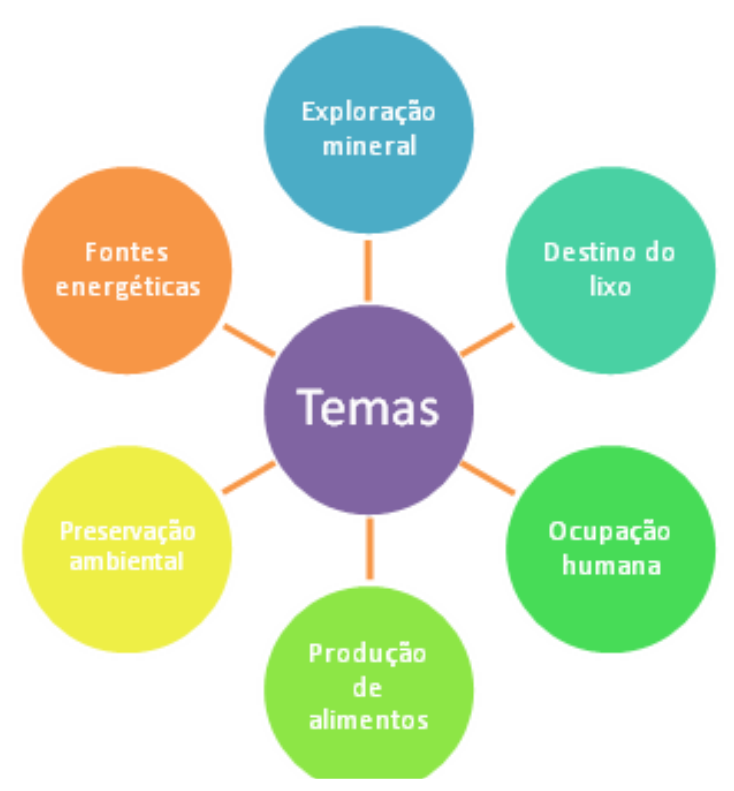

Fig. 01: Alguns dos temas a serem abordados segundo Santos (2002).

Como se vê, as propostas nessa direção são variadas, entretanto, compartiIham determinados aspectos de relevância social e abrangência local e nacional, com possibilidades para articulação em um contexto global. Com base neles, procuramos, na escolha de nosso tema, encontrar um denominador comum, que atendesse maximamente os critérios sugeridos pelos diversos autores descritos acima.

\subsection{ELABORAÇÃO DA SEQUÊNCIA DIDÁTICA}

Uma vez que a abordagem CTS é escolhida como estratégia de ensino, a elaboração da sequência didática deve ser concretizada com base na abordagem temática. Entretanto, como já foi dito, uma proposta de ensino CTS deve se diferenciar das propostas educacionais tradicionais não somente quanto aos objetivos traçados, mas, justamente em razão disso, também em sua formatação. Nesse sentido, seria recomendável buscaram-se métodos didáticos não tradicionais, que difiram das aulas expositivas, em que apenas o professor é o elemento ativo, ao passo que os alunos são personagens passivos do processo de aprendizagem.

Na medida em que visa a promover mais que o entendimento da ciência e da tecnologia, mas, principalmente, a compreensão de todos os aspectos que estão atrelados a estas, sociais, ambientais, históricos, econômicos, políticos, éticos e culturais, a educação CTS não pode construída somente a partir da mudança dos conteúdos programáticos; é essencial que ocorram mudanças também nos processos metodológicos e de avaliação, como, por exemplo, o uso de meios informais de divulgação científica em sala de aula, assim como visitas programadas a espaços não formais de educação (SANTOS, 2007).

Sendo assim, para a construção desta sequência didática devem ser pensados métodos e recursos alternativos aos tradicionalmente adotados nas escolas do país, de tal forma que o principal papel do professor deverá ser de mediador do processo de aprendizagem, que ocorreria por meio da ação dialógica entre professor e aluno; não haveria, pois, apenas, a "transferência" de conhecimentos e valores, mas uma construção de ideias com um propósito: a transformação da realidade.

Nesta estratégia, a problematização, ato de exercer uma análise crítica sobre a realidade problema (FREIRE, 1970), terá um papel essencial, pois será através dela que a realidade será desvelada. Ela será o elemento chave, a partir do qual se construirão o diálogo, o debate e os questionamentos, que resultarão em uma escolha consciente. Nestes termos se construirá a sequência didática.

Apesar de trazerem algo novo, essas aulas devem ter na sua construção a estrutura de planejamento de acordo com as normas de construção pedagógica, isto é, elas serão planejadas utilizando-se um modelo de plano de aula que contenha os seguintes elementos: local, data, subtema, assunto, duração, pré-requisitos, objeti- 
e-Mosaicos - Revista Multidisciplinar de Ensino, Pesquisa, Extensão e Cultura do Instituto de Aplicação Fernando Rodrigues da Silveira (CAp-UERJ)

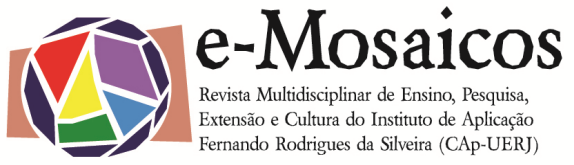

vos, recursos didáticos e verificação de aprendizagem.

Finalmente, em todos os casos, a forma específica das avaliações fica a critério do professor, respeitando as muitas especificidades envolvidas em cada processo educacional concreto.

\section{RESULTADOS E DISCUSSÃo}

\subsection{ESCOLHA DO TEMA}

Conforme bastante enfatizado nas seções anteriores, a escolha dos temas para uma abordagem CTS é elemento de primeira importância. Nesse sentido, coerentemente com os critérios lá apontados apresentamos como proposta de abordagem o tema "Produção de Energia Elétrica". É possível, antes de tudo, observar que este tema atende completamente os critérios estabelecidos por Ransey: é um tema extremamente controverso em sua atualidade, tendo em vista o enorme debate e a enorme militância ambiental voltados para os supostos impactos de cada forma de geração de energia; é de enorme interesse e abrangência social e constitui, de modo inequívoco, um problema estruturalmente relacionado a questões de ciência e tecnologia. Além disso, é uma grande temática que envolve, na realidade, vários temas presentes nas classificações de Merryfield, Towse, Bybee, Mau e Santa.

Além de todos os elementos já apontados, no caso específico do Estado do Rio de Janeiro esta temática está explicitamente indicada no Currículo Mínimo de Física da Secretaria de Estado de Educação (SEEDUC-RJ), que, de resto, recomenda o tratamento de impactos sociais e ambientais dos temas tratados, bem como o desenvolvimento de habilidades para a adoção de posturas críticas em relação a esses temas e para a tomada de decisões. Observa-se, nesse caso, uma completa adequação entre essas recomendações e os propósitos da educação CTS, abrindose, pois, espaço para a aplicação de tal abordagem.

Como já dito, a produção de energia elétrica é um tema de grande relevância. Por exemplo, em Angra dos Reis localiza-se a única usina nuclear do país com dois reatores em funcionamento e um terceiro em construção, de modo que a comunidade da região é diretamente impactada por este modo de produção. Contudo, ela não tem consciência plena desses impactos, nem tampouco dos riscos que a presença de uma usina nuclear acarretar, o que torna extremamente importante a abordagem do tema para os estudantes que vivem na região.

Como também já salientado, o tema da produção de energia, em suas várias modalidades tem uma relevância nacional e mundial. No contexto nacional brasileiro, as hidrelétricas se destacam como fonte energética. Existem, hoje, no Brasil, mais de 900 usinas hidrelétricas em funcionamento, correspondendo a $80 \%$ da oferta total de energia do país, desde pequenas centrais hidrelétricas $(\mathrm{PCH})$ até usinas hidrelétricas de grande porte (U$\mathrm{HE}$ ). A importância das hidrelétricas para o país é indiscutível, mas, ao mesmo tempo, impõe, também, a discussão de todas as implicações deste modo de produção.

Embora as usinas hidrelétricas e nucleares ganhem especial destaque nessa análise, devido a sua importância dentro contexto em que a proposta será aplicada, é preciso, contudo, discutir as demais formas de produção de energia, para que os alunos possam conhecer outras possibilidades, avaliar vantagens e desvantagens e comparar as diferentes fontes energéticas. Assim sendo, recomenda-se, também, o estudo dos diversos impactos de usinas termoelétricas, usinas de energia solar, usinas eólicas e usinas de ondas.

Diante de todo o exposto, o tema central Produção de Energia Elétrica foi 
dividido em três subtemas: "Usinas Hidrelétricas", "Outras Formas de Produção de Energia" e "Usinas Nucleares".

Ao dividir o tema central em subtemas mais específicos foi possível aproximar a discussão do contexto local, através do item "Usinas Nucleares", ou ainda expandir para o contexto nacional, abordando as usinas hidrelétricas, ainda que ambos possam ser ampliados para o contexto global. Mesmo assim, o subtema "Outras Formas de Produção de Energia" também pode ser tratado em ambos os contextos. As implicações dos diversos modos de produção de energia possuem não somente aspectos sociais, como também ambientais, econômicos, éticos, políticos, culturais e históricos a serem explorados que enriquecerão a abordagem. Este tema permite ainda o tratamento de fenômenos e conceitos físicos presentes em nosso dia e que serão de extrema importância para sua compreensão

De acordo com as recomendações do currículo mínimo de física do Rio de Janeiro, os subtemas foram organizados de acordo com uma sequência cronológica de aplicação que aborde pelo menos três formas distintas de energia (Fig. 01).

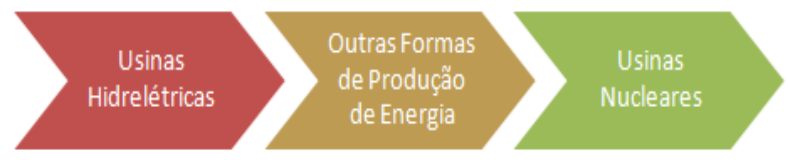

Fig 03. Onde de abordagem das diferentes fontes de geração de energia.

\subsection{ELABORAÇÃO DA SEQUÊNCIA DIDÁTICA}

A sequência didática foi elaborada no sentido de envolver atividades de naturezas diversas que priorizem 0 debate, 0 diálogo, a atividade em grupo e a participação ativa do aluno, de modo que o professor seja apenas o mediador do processo de aprendizagem, problematizando, questionando e incentivando a participa- ção dos alunos. Nesta sequência, o objetivo será a compreensão dos diversos processos de produção de energia elétrica e suas implicações, pretendendo-se não somente a compreensão dos fenômenos e conceitos físicos envolvidos, mas, também, os impactos sociais em seus diversos planos, buscando provocar a reflexão sobre esses aspectos com vistas à tomada de decisões e à ação social responsável a respeito do tema.

Os subtemas devem ser introduzidos por meio da problematização, com o auxílio de novos recursos didáticos. Atualmente, existe um mundo virtual, acessível pela rede mundial de computadores (internet), onde é possível encontrar a qualquer momento diversos materiais e recursos, como vídeos, aplicativos e jogos didáticos, documentários, imagens, entre outros, sobre os mais variados assuntos. Deste modo, em muitas situações, "não são necessários laboratórios sofisticados, grade horária ampliada e incorporação de novos conteúdos" para que mudanças efetivas ocorram, "mas sim mudanças de propósitos em sala de aula" (SANTOS, 2007).

Na nossa proposta os vídeos são os recursos mais utilizados por diversos motivos, destacando-se:

- Não é possível explicar o que são ou como são usinas hidrelétricas, usinas nucleares, termoelétricas, entre outros modos de produção de energia, para alguém que nunca as tenha visto. Poderiam ser utilizadas apenas fotos, porém não teriam o mesmo impacto visual e dinamicidade que os vídeos.

- Os vídeos escolhidos são acessíveis para qualquer pessoa e disponíveis na página de vídeos Youtube $e$ podem ser baixados de modo a serem exibidos mesmo sem conexão com a internet,

- Para trabalhar com os vídeos em 
e-Mosaicos - Revista Multidisciplinar de Ensino, Pesquisa, Extensão e Cultura do Instituto de Aplicação Fernando Rodrigues da Silveira (CAp-UERJ)

sala de aula são necessários apenas um projetor digital (datashow) e um computador com som ou uma televisão, recursos que fazem parte da realidade de muitas escolas, mesmo públicas. 0 professor teria ainda conveniências de portabilidade, pois precisaria apenas transportar seu dispositivo de mídia removível (pen-drive) com os vídeos e não materiais em excesso;

- Por meio dos vídeos é possível apresentar imagens reais das usinas e simulações de eventos históricos que ocorreram ao longo dos tempos e hoje estão disponíveis na rede.

Embora os vídeos tenham presença marcante na sequência de aulas, foram utilizados outros métodos e recursos didáticos, como, por exemplo, um aplicativo virtual em linguagem Java ${ }^{\circledR}$ (applet), visitas a espaços não formais de educação, debates e outras atividades em grupo.

A seguir é apresentada a proposta de ordenamento das aulas (Fig. 04), com os objetivos claros todos os aspectos considerados para o planejamento de cada aula, separados em dentro dos grupos já citados (Fig. 01).

\begin{tabular}{|c|c|}
\hline Aula 1 & $\begin{array}{l}\text { - Usinas Hidrelétricas/Como funciona/A Batalha de } \\
\text { Belo Monte }\end{array}$ \\
\hline Aula 2 & -Vantagens e desvantagens das usinas hidrelétricas \\
\hline Aula 3 & -Vantagens e desvantagens das usinas hidrelétricas \\
\hline Aula 4 & -Transformação de energia \\
\hline Aula 5 & $\begin{array}{l}\text { - Energia mecânica, energia potencial e energia } \\
\text { cinética }\end{array}$ \\
\hline Aula 6 & $\begin{array}{l}\text {-Usinas Termoelétricas, usinas de energia solar, } \\
\text { usinas eólicas e usina de ondas }\end{array}$ \\
\hline Aula 7 & $\begin{array}{l}\text {-Usinas termoelétricas, usinas solares, usinas } \\
\text { eólicas e usinas de ondas }\end{array}$ \\
\hline Aula 8 & -Acidente na Usina Nuclear de Chernobyl \\
\hline Aula 9 & -Bomba atômica \\
\hline Aula 10 & -Reações Nucleares \\
\hline Aula 11 & -Usina nuclear \\
\hline Aula 12 & -Acidente em Goiania (Césio 137) \\
\hline Aula 13 & -Radioatividade \\
\hline Aula 14 & -Vantagens e desvantagens das usinas nucleares \\
\hline
\end{tabular}

Fig. 04 - Ordenamento das aulas propostas. 
Através do subtema "Usinas Hidrelétricas", que será abordado nas aulas de 1 a 4, os alunos poderão conhecer as usinas hidrelétricas e seu funcionamento, permitindose discutir os possíveis impactos negativos causados por elas. Dentro desse grupo de aulas, é importante que haja atividades de procura em jornais, revistas ou na internet notícias sobre as hidrelétricas para discussão em sala. Para construção da discussão desses temas serão utilizados como apoio os vídeos: "O Brasil e suas usinas hidrelétricas" (YOUTUBEa , 2016), "Como funciona uma usina hidrelétrica-1" (YOUTUBE ${ }^{\mathrm{b}}$, 2016), "Como funciona uma usina hidrelétrica-2" (YOUTUBE", 2016), "Hidrelétrica: Principal fonte de energia do Brasil" (YOUTUBE" , 2016), "As 10 maiores hidrelétricas do mundo" (YOUTUBE , 2016), "Movimento Gota D'água" (YOUTUBE $\left.{ }^{f}, 2016\right)$ e "A Batalha de Belo Monte" (YOUTUBEg", 2016).

$\mathrm{Na}$ etapa relacionada ao subtema "Outras formas de Produção de Energia", compreendida entre as aulas 5 e 7, são abordadas as transformações de alguma forma de energia em energia elétrica, buscando levar os estudantes a compreender as diferenças de cada modo de produção, com suas vantagens e desvantagens. Será especialmente importante nesse subtema a possibilidade de se abordar a geração eólica, pois através dessa análise podemos discutir os princípios ligados ao movimento circular. O processo de produção de energia por queima de compostos também é de fundamental importância, visto que aqui podem ser discutidas questões ambientais e econômicas mais complexas, envolvendo os processos de extração de carvão mineral, importação e produção de gás natural, bem como a produção de outros biocombustíveis. Para esse grupo de aulas sugerimos a utilização dos vídeos: "Usina Termoelétrica Jorge Lacerda", (YOUTUBE" , 2016), "Usinas Termoelétricas", (YOUTUBE', 2016), "Termoelétri- cas Pecém", (YOUTUBEj, 2016), "Usina de Ondas", (YOUTUBEk , 2016), "Usina de Energia Solar", (YOUTUBE', 2016) e (YOUTUBE $^{\mathrm{m}}$, 2016).

Nesse grupo de aulas trabalharemos aspectos mais técnicos dos conteúdos. Assim, uma vez conhecidos os processos de produção de energia elétrica nas usinas hidrelétricas, os alunos poderão discutir com mais facilidade os conceitos de energia mecânica, energia cinética e energia potencial, bem como suas formulações matemáticas e unidades. Essa etapa será fundamental para abordarmos as expressões e conversões de unidades de medida de energia.

Para avaliar a aprendizagem referente às aulas anteriores, será aplicada uma lista de exercícios sobre energia mecânica, energia cinética e energia potencial gravitacional. No entanto, os exercícios serão do modelo tradicional, encontrados, geralmente, em livros didáticos, vestibulares e outros testes, utilizando bolinhas, móveis e partículas para o cálculo da energia associada ao movimento desses objetos. Foram escolhidos estes modelos de exercícios a fim de verificar se, após a apresentação dos conceitos e equações utilizando exemplos reais, os alunos seriam capazes de transferir o conhecimento do concreto para o abstrato.

O último subtema a ser trabalhado que se refere a Usinas Nucleares, tema das aulas $8,9,10,11,12,13$ e 14 . Este é um assunto de vital importância dentro do elemento de contextualização em que se situa a proposta aqui apresentada, tendo em vista o público a que se destina. Novamente, o objetivo principal é fazer os alunos as vantagens e desvantagens desta modalidade de produção de energia, a partir da motivação concreta proporcionada pela proximidade geográfica da Usina de Angra dos Reis com a comunidade. 
e-Mosaicos - Revista Multidisciplinar de Ensino, Pesquisa, Extensão e Cultura do Instituto de Aplicação Fernando Rodrigues da Silveira (CAp-UERJ)

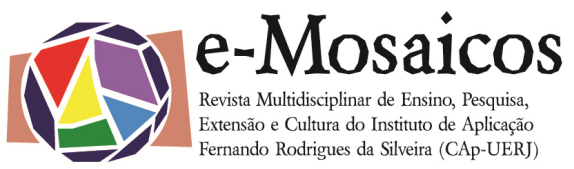

Primeiramente, temos a possibilidade de apresentar o funcionamento de um reator e de todo o processo de produção nuclear, o que pode ser feito com a utilização do aplicativo em linguagem Javaß
"Fissão Nuclear" (Fig. 05) (UC, 2012), que permite mostrar o processo básico de formação operação de um reator e do efeitos de fissão nuclear, bem como da reação em cadeia

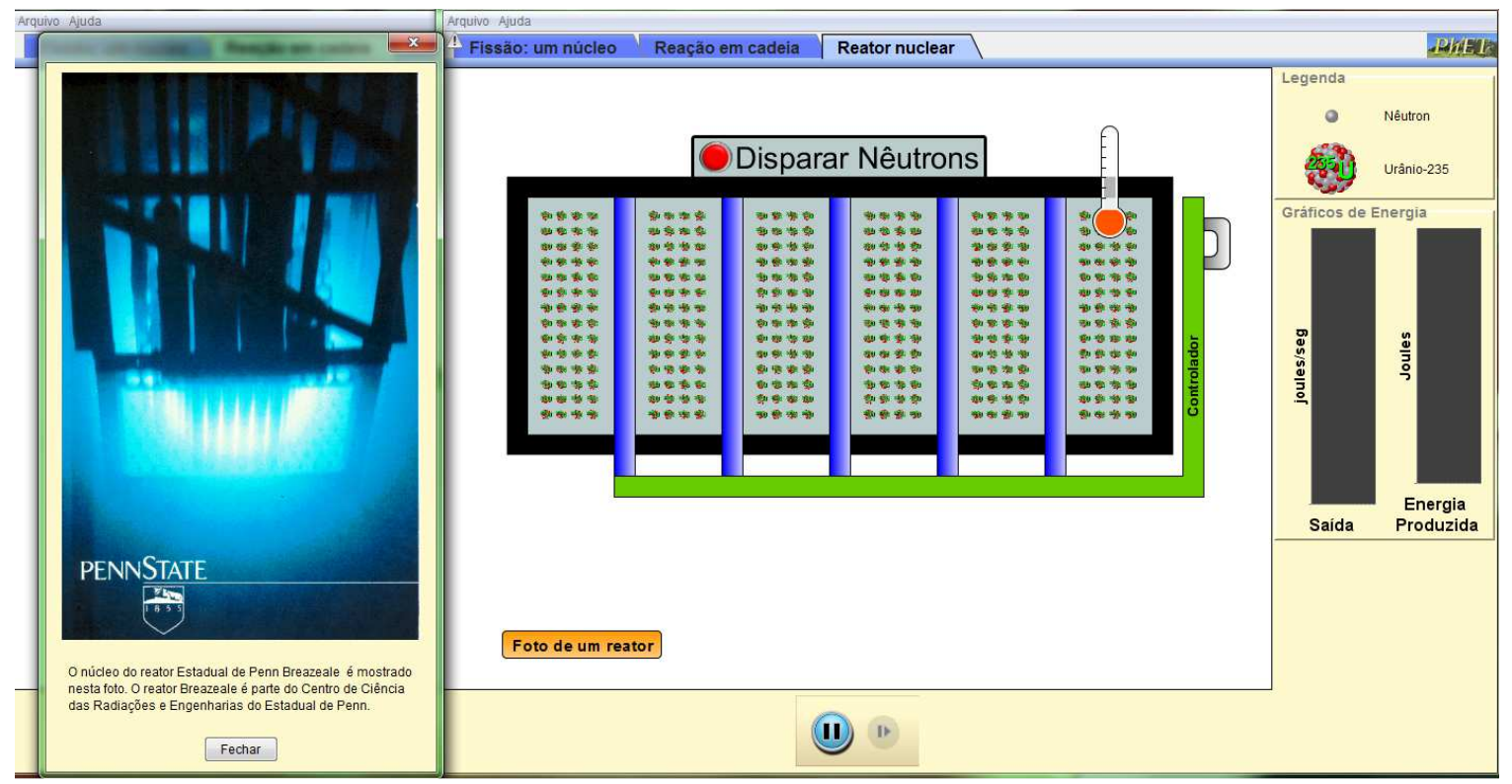

Fig. 05 - Apresentação do aplicativo em linguagem Java ${ }^{\circledR}$ utilizado na atividade.

A compreensão do processo de produção nos dá condições de provocar uma reflexão sobre os riscos que oferece uma usina nuclear, mostrando as condições que podem determinar a ocorrência de acidentes e as consequências da exposição à radiação. Também nos oferece a oportunidade de questionar o impacto ambiental dessa atividade, com a destinação dos rejeitos nucleares e da água utilizada no processo de resfriamento do reator, entre outros. Aqui os alunos serão levados a compreender a importância de a tecnologia ser manipulada com bom-senso e segurança e que muitas vezes os interesses econômicos e políticos prevalecem sobre preocupações de segurança na tomada de decisões.

A abordagem sobre a energia nuclear deve trazer a reflexão sobre o uso militar de bombas nucleares, trazendo uma ligação com temas históricos e levar os alunos a refletir sobre o uso da ciência e tecnologia como instrumento de poder e dominação.

No caso dos alunos das escolas públicas da região de Angra do Reis e adjacências um elemento didático a mais está na possibilidade de visitação da usina nuclear. Embora o acesso seja extremamente limitado, já que se trata de menores de idade, lá os alunos podem assistir alguns vídeos que apresentam a usina, o funcionamento do reator e o processo de geração de energia elétrica, enfatizandose as vantagens deste tipo de usina, os cuidados com o meio ambiente e com o lixo nuclear e a segurança da população da cidade.

As três últimas aulas trazem relação com temas ligados à radioatividade. importantes dentro do cenário de proteção 
radiológica. São apresentadas as ideia de decaimento radioativo e questões de proteção e segurança radiológica. Além do aplicativo já mencionado, como apoio será utilizado o vídeo intitulado "Césio 137" (YOUTUBE ${ }^{\mathrm{n}}, 2016$ ).

Essa estrutura de organização de aulas traz com ela a possibilidade de se construir e levar aos alunos uma forma de aprendizagem fortemente apoiada em um aspecto visual, que é um elemento importantíssimo de interação com a informação nos dias atuais. A atual forma de interação por meio de mídias sociais faz com que as novas gerações respondam bem a processos visuais, fazendo com que tenham mais interesses nas informações e criando um ambiente favorável para discutir as bases conceituais de temas complexos e necessários para sua formação.

\section{CONCLUSÃo}

As implicações recíprocas entre ciência, tecnologia e sociedade são inúmeras e profundas. Assim sendo, os processos decisórios relacionados a questões científicas jamais podem ser delegadas a uma autoridade tecnocrática, supostamente racionalmente isenta. Em lugar disso, a educação CTS propõe a alfabetização e a conscientização científica da sociedade, de forma a proporcionar as condições de sua participação ativa nas escolhas que the afetam.

Com base nisso, neste trabalho fazemos uma proposta de abordagem CTS para o ensino de Física em um contexto local específico: uma escola pública do município de Angra dos Reis, RJ. Tendo em vista a particularidade da localização de uma usina nuclear na região e dos impactos reais e potenciais a ela relacionados, escolhemos por abordar um tema relacionado de forma mais imediata à realidade local: a produção de energia elétri$\mathrm{ca}$, em suas diferentes modalidades.
Apresentamos, pois, uma proposta de sequência didática com essa inspiração, composta por quatorze aulas, de forma a abarcar um bimestre letivo. Para cada aula são apresentados os objetivos e são sugeridas atividades, devidamente fundamentadas nos termos dessa concepção e enfatizando o uso de métodos alternativos e de base dialógica, com vistas a promover o senso de participação e de tomada de decisões.

\section{REFERÊNCIAS BIBLIOGRÁFICAS}

BYBEE, R. W., MAU, T. Science and technology related global problems: na international survey of science educators. Journal of Research in Science Teaching, v. 23, n. 7, p.599-618, 1986.

CHASSOT, A. Alfabetização científica: questões e desafios para a educação. Ijuí: Editora UNIJUÍ, 2000.

CHRISPINO, A. Ciência, Tecnologia e Sociedade. Rio de Janeiro: CEFET/RJ, 2009.

DELIZOICOV, D.; ANGOTTI, J. A.; PERNAMBUCO, M. M. Ensino de Ciências: fundamentos e métodos. São Paulo: Cortez, 2002.

FOUREZ, G. A construção das ciências Introdução à filosofia e à ética das ciências.

São Paulo: UNESP, 1995.

FREIRE, P. Pedagogia do Oprimido. Rio de Janeiro: Paz e Terra, 1970.

FREIRE, P. Pedagogia do Oprimido, 17 ed. Rio de Janeiro: Paz e Terra, 1987.

FREIRE, P. Pedagogia da Autonomia: saberes necessários à prática educativa. São Paulo: Paz e Terra, 1996. 
HABERMAS, J., Técnica e Ciência como Ideologia. São Paulo: UNESP, 2014.

KRASILCHIK, M.; MARANDINO, M. Ensino de Ciências e Cidadania. São Paulo: Ed. Moderna, 2004.

MORAN, J. M. O Vídeo na Sala de Aula. Comunicação \& Educação. p. 27-35, 1995.

MAZZUCATO, M., O Estado Empreendedor. São Paulo: Portfolio Penguin, 2014.

MERRYFIELD, M. M. Science-TechnologySociety and Global Perspectives. Theory into Practice, v. 30, n. 4, p.288-293, 1991.

PATRONIS, T.; POTARI, D.; SPILIOTOPOULOU, V. Students' Argumentation in Decision - Making on a Socio-scientific Issue: Implications for Teaching. International Journal of Science Education, v.21, n.7, p.745-54, 1999.

RAMSEY, J. The Science Education Reform Movement: Implications for Social Responsibility. Science Education, v. 77, n. 2, p. 235-258, 1993.

RUBBA, P. Integration STS Into School Science and Teacher Education: Beyond Awareness. Theory into Practice, v. 30, n. 4, p. 303-315, 1991.

SANTOS, W. L. P. dos; MORTIMER, E. F. Tomada de decisão para ação social responsável no ensino de ciências. Ciência $e$ Educação, v. 7, n. 1, p. 95-111, 2001.

SANTOS, W. L. P. dos; MORTIMER, E. F. Uma análise de pressupostos teóricos da abordagem C-T-S (Ciência-TecnologiaSociedade) no contexto da educação brasileira. ENSAIO - Pesquisa em Educação em Ciências, v. 2, n. 2. Dezembro, 2002.

SANTOS, W. L. P. dos; SCHNETZLER, R. P. A formação do cidadão e o ensino de CTS - Ciência, Tecnologia e Sociedade. Educa- ção em química: compromisso com a cidadania. 3. ed. Ijuí: Unijuí, 2003.

SANTOS, W. L. P. Educação Científica na perspectiva de letramento como prática social: funções, princípios e desafios. $R e$ vista Brasileira de Educação, v. 12, n. 36, set./dez. 2007.

SANTOS, W. L. P. Educação Científica Humanística em Uma Perspectiva Freireana: Resgatando a Função do Ensino de CTS. Alexandria Revista de Educação em Ciência e Tecnologia, v. 1, n. 1, p. 109-131, mar. 2008.

SEEDUC - Secretaria de Estado de Educação do Rio de Janeiro. Currículo Mínimo de Física, 2012.

TOWSE, P. J. International Newsletter on Chemical Education - IUPAC, n. 2, p.2-3, 1986.

UC - University Colorado. Fissão Nuclear: Fissão Nuclear, 2012. Disponível em: https://goo.gl/AUZJtk, Acesso em: 15 jul. 2016.

WAKS, L. J. Educación en ciencia, tecnología y sociedad: orígenes, dessarrollos internacionales y desafíos actuales. MEDINA, M.; SANMARTÍN, J. (Eds.). Ciencia, tecnologia y sociedad: estudios interdisciplinares en la universidad, en la educación y en la gestión pública. Barcelona: Anthropos/Leioa (Vizcaya): Univesidad del País Vasco, p.42-75, 1990.

YOUTUBE ${ }^{\mathrm{a}}$. O Brasil e suas usinas hidrelétricas. Disponível em: https://goo.gl/OYd3nk, Acesso em: 07 jan. 2016.

YOUTUBE ${ }^{\mathrm{b}}$. Como funciona uma usina hidrelétrica-1. Disponível em: https://goo.gl/oCMunN, Acesso em: 07 jan. 2016. 
YOUTUBE ${ }^{\mathrm{C}}$. Como funciona uma usina hidrelétrica-2. Disponível em: https://goo.gl/CZYnEd, Acesso em: 07 jan. 2016.

YOUTUBE ${ }^{d}$. Hidrelétrica: Principal fonte de energia do Brasil. Disponível em: https://goo.gl/Gnpkwb, Acesso em: 07 jan. 2016.

YOUTUBE ${ }^{\mathrm{e}}$. As 10 maiores hidrelétricas do mundo. Disponível em: https://goo.gl/96NWKj, Acesso em: 07 jan. 2016.

YOUTUBE ${ }^{f}$. Movimento Gota D'água. Disponível em: https://goo.gl/bd5GfD, Acesso em: 07 jan. 2016.

YOUTUBE $^{g}$. A Batalha de Belo Monte. Disponível em: https://goo.gl/4kFpUk, Acesso em: 07 jan. 2016.

YOUTUBE ${ }^{\mathrm{h}}$. Usina Termoelétrica Jorge Lacerda. Disponível em: https://goo.gl/AuuHmh, Acesso em: 07 jan. 2016.
YOUTUBE'. Usinas Termoelétricas. Disponível em: https://goo.gl/EeiYjq, Acesso em: 07 jan. 2016.

YOUTUBE ${ }^{\mathrm{j}}$. Termoelétricas Pecém. Disponível em: https://goo.gl/38dFIS, Acesso em: 07 jan. 2016.

YOUTUBE ${ }^{k}$. Usina de Ondas. Disponível em: https://goo.gl/OTZbA1, Acesso em: 07 jan. 2016.

YOUTUBE'. Usina de Energia Solar. Disponível em: https://goo.gl/o7U8t4, Acesso em: 07 jan. 2016.

YOUTUBE" ${ }^{\mathrm{m}}$. Rumos da Produção de Energia Elétrica no Brasil. Disponível em: https://goo.gl/sZzq86, Acesso em: 07 jan. 2016.

YOUTUBE ${ }^{n}$. Césio 137. Disponível em: https://goo.gl/cQv5HW, Acesso em: 07 jan 2016. 


\section{APÊNDICE}

\section{AULA 1}

Subtema: Usinas Hidrelétricas

Assunto: Usina Hidrelétrica/Como funciona/A Batalha de Belo Monte

Pré-requisitos. Não são necessários conhecimentos prévios para a compreensão desta aula.

Objetivos. Apresentar aos alunos as usinas hidrelétricas e seu funcionamento. Apresentar as dez maiores hidrelétricas do mundo, para que descubram que as hidrelétricas brasileiras estão entre as maiores. Apresentar o vídeo de divulgação do Movimento Gota D'água para levantar questionamentos sobre os impactos negativos causados pelas hidrelétricas e para introduzir a polêmica da construção da Usina Hidrelétrica Belo Monte. Apresentar um documentário que apresenta a situação real da Usina Belo Monte, para que os alunos, ao conhecerem os impactos de sua construção, possam opinar a respeito.

Desenvolvimento do tema: Serão exibidos sete vídeos durante a aula: "Usina Termoelétrica Jorge Lacerda", (YOUTUBE $\left.{ }^{\mathrm{h}}, 2016\right)$, "Usinas Termoelétricas", (YOUTUBE', 2016), "Termoelétricas Pecém", (YOUTUBE", 2016), "Usina de Ondas", (YOUTUBEk , 2016), "Usina de Energia Solar", (YOUTUBE', 2016) e (YOUTUBE"m , 2016). Após a exibição dos cinco primeiros vídeos, serão levantados algumas questões para debate. Em seguida, será exibido o sexto vídeo e, então, novos questionamentos serão levantados. Por fim, o último vídeo será exibido e, em seguida, será dada continuidade ao debate.

\section{AULA 2}

Subtema: Usinas Hidrelétricas

Assunto: Vantagens e desvantagens das usinas hidrelétricas

Pré-requisitos. É necessário que os alunos tenham participado da Aula 1, ou tenham assistido os vídeos apresentados em casa.

Objetivos. Através de uma atividade em grupo, promover a discussão sobre vantagens e desvantagens, levando a uma tomada de decisão a favor ou contra as usinas hidrelétricas.

Desenvolvimento do tema: Na aula anterior, deverá ser solicitado aos alunos que procurem notícias sobre hidrelétricas, em jornais, revistas ou na internet, e levem impressas para esta aula. Cada aluno deverá levar pelo menos uma notícia. A turma será dividida em grupos de quatro pessoas. Para dividir os grupos será usado o seguinte critério: os alunos terão que se posicionar se são contra ou a favor das hidrelétricas e os grupos serão formados por alunos que tenham a mesma posição. Então, cada grupo irá confeccionar um cartaz para defender ou criticar as hidrelétricas, utilizando as notícias que trouxeram. 


\section{AULA 3}

Subtema: Usinas Hidrelétricas

Assunto: Vantagens e desvantagens das usinas hidrelétricas

Pré-requisitos. É necessário que os alunos tenham participado da aula 2.

Objetivos. Apresentar para a turma os cartazes confeccionados pelos grupos na aula anterior, promovendo, desta forma, um debate sobre as vantagens e desvantagens das usinas hidrelétricas. Promover a divulgação e conscientização das demais turmas da escola através da exposição dos cartazes.

Desenvolvimento do tema: Após a confecção dos cartazes na aula anterior, os grupos irão apresentar seus cartazes, justificando suas opiniões, gerando, deste modo, um debate, que será conduzido pelo professor. Em seguida, os cartazes serão expostos na escola para divulgação e conscientização das demais turmas.

\section{AULA 4}

Subtema: Usinas Hidrelétricas

Assunto: Transformação de energia

Pré-requisitos. É necessário que os alunos compreendam os conceitos de altura, velocidade, massa, área, volume e densidade, bem como conheçam suas respectivas unidades. É importante que tenham participado das aulas anteriores, porém, não ter participado não será um impeditivo para compreensão desta aula.

Objetivos. Apresentar aos alunos as seis maiores hidrelétricas do Brasil e algumas de suas características. A partir dos dados técnicos dessas usinas, fazê-los compreender a relação entre a altura, vazão e capacidade produção de energia elétrica. Introduzir os conceitos de energia potencial, energia cinética, energia mecânica e potência elétrica.

Desenvolvimento do tema: Serão distribuídos aos alunos dados técnicos sobre as seis maiores usinas hidrelétricas do Brasil. Cada dupla ou trio receberá uma folha constando nome, foto, localização, capacidade de produção, altura da queda d'água, vazão, quantidade de turbinas e tipo de turbina de uma das dez usinas escolhidas. Em seguida, a professora irá montar uma tabela no quadro, solicitando os dados aos alunos, ordenando essas 6 usinas em relação a sua capacidade de produção.

\section{AULA 5}

Assunto: Energia mecânica, energia potencial e energia cinética.

Pré-requisitos. É necessário que os alunos tenham compreendido os conceitos de energia mecânica, energia cinética e energia potencial, bem como suas equações e unidades.

Objetivos. Resolver exercícios sobre energia mecânica, energia cinética e energia potencial.

Desenvolvimento do tema: Será entregue aos alunos uma lista de exercícios (anexo) impressa sobre energia mecânica, energia potencial e energia cinética. O professor irá resol- 
ver e explicar alguns, sempre associando-a ao tema "Produção de Energia", e, em seguida, os alunos irão resolver os outros sozinhos, ou com a ajuda dos colegas, para entregar como sugestão de forma de avaliação.

\section{AULA 6}

subtema: Outros modos de produção de energia

Assunto: Usinas Termoelétricas, usinas de energia solar, usinas eólicas e usina de ondas

Pré-requisitos. Ter compreendido como é o processo de produção de energia nas usinas hidrelétricas.

Objetivos. Apresentar aos alunos outros modos de produção de energia, tais como usinas termoelétricas e os diversos combustíveis utilizados, usinas de energia solar, usinas eólicas e usina de ondas. Promover um debate sobre vantagens e desvantagens dos diversos modos de produção de energia elétrica.

Desenvolvimento do tema: Serão apresentados seis vídeos durante esta aula. Nos intervalos entre os vídeos serão levantados questionamentos com o objetivo de incentivar o debate entre os alunos.

\section{AULA 7}

subtema: Outros modos de produção de energia

Assunto: Usinas termoelétricas, usinas solares, usinas eólicas e usinas de ondas

Pré-requisitos: Será assumido que os alunos compreendem os conceitos de potência, pressão e trocas de calor, porém não é necessário que saibam calcular tais grandezas.

Objetivos. Apresentar os fenômenos físicos envolvidos nas usinas termoelétricas, eólicas, usina de ondas e usinas solares. Mostrar que todos os processos de geração de energia elétrica representam um processo de transformação de alguma forma de energia em energia elétrica e não uma geração propriamente dita. Levá-los a compreender as diferenças de cada modo de produção em relação aos fenômenos envolvidos discutir todos os aspectos envolvidos.

Desenvolvimento do tema: A aula será apresentada em slides. Será apresentado o processo de geração de energia através das usinas termoelétricas, evidenciando a transformação de energia térmica em energia elétrica. Serão apresentados os diversos tipos de combustíveis que podem ser utilizados nestas usinas, dando ênfase aos seus diferentes impactos e suas vantagens. Serão abordados os processos de extração de carvão mineral, importação e produção de gás natural, bem como de produção de outros biocombustíveis. Será apenas comentado que a usina nuclear também é uma termoelétrica, que apenas utiliza outro tipo de combustível, porém esse assunto será aprofundado nas próximas aulas. Em seguida, serão abordados os processos de geração de energia através das usinas solares, eólicas e de ondas, apresentando os principais aspectos de cada um, suas vantagens e desvantagens, seus impactos e suas limitações. Serão apresentadas centrais domésticas de produção de energia que utilizam energia solar ou eólica e discutidas suas possibilidades, custos, vanta- 
gens, entre outras questões que surgirem durante a aula. O professor irá incentivar a participação dos alunos com perguntas sobre o assunto durante toda a aula.

\section{AULA 8}

subtema: Usinas Nucleares

Assunto: Acidente na Usina Nuclear de Chernobyl

Pré-requisitos. Não são necessários pré-requisitos para compreensão desta aula, pois trata-se do relato de um acontecimento histórico. Alguns conceitos citados no documentário serão abordados nas aulas seguintes.

Objetivos. Apresentar aos alunos um documentário sobre o acidente ocorrido na Usina Nuclear de Chernobyl para fazê-los refletir sobre os riscos que oferece uma usina nuclear. Apresentar o funcionamento de um reator. Mostrar que um acidente não acorre apenas por falta de segurança e controle, mas também por erros de operação (erros humanos). Mostrar as consequências da exposição à radiação nuclear. Levá-los a refletir sobre a importância de a tecnologia ser manipulada com bom-senso e segurança. Mostrar que muitas vezes os interesses econômicos e políticos prevalecem sobre as medidas de segurança na tomada de decisões em ciência e tecnologia.

Desenvolvimento do tema: O documentário exibido em vídeo tem duração de 45 minutos e apresenta uma simulação do acidente ocorrido na Usina Nuclear de Chernobyl em 26 de abril de 1986. Além da simulação, o vídeo apresenta uma narração que conta detalhes sobre o acidente. São apresentados depoimentos de vítimas e até mesmo do trabalhador responsabilizado pelo acontecimento. O documentário mostra a sala de controle do reator e como é feita a operação do mesmo. Por meio de animações, são mostrados o interior do reator e os fenômenos que resultaram na ocorrência do acidente. São apresentados detalhes sobre a vida pessoal e política do engenheiro chefe do reator que indicam que esses fatores contribuíram em favor do acidente. $O$ vídeo mostra também imagens reais das operações de contenção da radiação e de como ficou o local após o acidente.

\section{AULA 9}

subtema: Usinas Nucleares

Assunto: Bomba atômica

Pré-requisitos. Não são necessários pré-requisitos para compreensão desta aula, pois trata-se do relato de um acontecimento histórico. Alguns conceitos citados no documentário serão abordados nas aulas seguintes.

Objetivos. Apresentar aos alunos um documentário sobre o lançamento da bomba atômica em Hiroshima, no Japão. Apresentar o contexto em que ocorreu o lançamento da bomba nuclear. Introduzir os fenômenos envolvidos na construção da bomba atômica. Mostrar o procedimento realizado para o ataque. Levar os alunos a refletir sobre o uso da ciência e tecnologia como instrumento de poder e dominação. Apresentar as consequências da expo- 
sição à radiação em excesso. Mostrar que a tecnologia utilizada na bomba atômica é a mesma da usina nuclear.

Desenvolvimento do tema: O documentário exibido em vídeo tem duração de 40 minutos e relata o lançamento de uma bomba atômica na cidade de Hiroshima, no Japão, ocorrido em 6 de agosto de 1945. O vídeo narra o acontecimento com detalhes sobre os efeitos que a bomba causou, incluindo relatos de vítimas e de soldados que participaram da operação de lançamento. São mostradas imagens reais do dia seguinte após o ataque. São apresentados dados sobre a quantidade de vítimas fatais e feridos, bem como os efeitos sobre o local. São apresentados os efeitos da exposição à radiação. Após o vídeo o professor irá relacionar os dois acontecimentos (o acidente na usina nuclear e o lançamento da bomba) apontando as relações entre eles, não somente em relação aos fenômenos físicos, mas também sobre as relações de poder.

\section{AULA 10}

subtema: Usinas Nucleares

Assunto: Reações Nucleares

Pré-requisitos. Será assumido que os alunos tenham estudado átomos e suas características, bem como conheçam a tabela periódica.

Objetivos. Levar os alunos a compreender a origem da energia nuclear, das reações nucleares e do funcionamento de um reator. Apresentar os processos envolvidos na geração de energia elétrica por meio da usina nuclear, os problemas e vantagens deste tipo de usina. Ajudá-los a compreender as causas técnicas do acidente ocorrido na Usina Nuclear de Chernobyl.

Desenvolvimento do tema: A aula será apresentada em slides. Inicialmente, será exposta a estrutura do átomo, identificando prótons, nêutrons e elétrons e as partículas que constituem os dois primeiros, os quarks, identificando assim a origem da força nuclear. Serão então introduzidas as reações nucleares, de fissão e fusão nuclear, diferenciando os dois tipos de reação e explicando como ocorre cada uma. Será explicado como ocorre a reação em cadeia e os elementos que são utilizados no processo. Será apresentado o processo de enriquecimento do urânio e explicada a diferença entre o combustível utilizado na usina nuclear e na bomba atômica. Será, então, apresentado o funcionamento de um reator nuclear e todo o processo para transformação de energia nuclear em energia elétrica que ocorre na usina. Serão comparados os combustíveis de vários tipos de usinas e explicado sobre a geração, armazenamento e problemas do lixo nuclear. Em seguida, será explicado mais detalhadamente o processo de fusão nuclear, exemplificando onde ele ocorre na natureza e como a ciência tem tentado reproduzí-lo. Para finalizar, será discutido novamente o acidente ocorrido na Usina Nuclear de Chernobyl para preparação à visita na Usina Nuclear de Angra dos Reis, porém agora com uma ênfase maior nos processos internos dos reatores e relembrando as causas do acidente apresentadas no documentário. Para melhor compreensão da reação em cadeia e do funcionamento do reator, será utilizado um aplicativo virtual que simula estes processos (applet). 


\section{AULA 11}

subtema: Usinas Nucleares

Assunto: Usina nuclear

Pré-requisitos: Será assumido que os alunos tenham compreendido o funcionamento do reator, bem como todos os processos envolvidos na geração de energia elétrica por meio de uma usina nuclear.

Objetivos. Conhecer a Usina Nuclear de Angra dos Reis, levantar questionamentos a respeito dos riscos, do controle, da segurança, dos impactos ao meio ambiente, do destino do lixo nuclear, entre outros. Mostrar aos alunos que as informações passadas à sociedade pela usina nem sempre refletem a situação real.

Desenvolvimento do tema: A visitação da usina nuclear (centro de informações) tem duração de 2 horas. Os alunos são autorizados apenas a visitar o centro de informações, devido ao fato de serem menores de idade. Os alunos assistem a alguns vídeos, que apresentam a usina nuclear, o funcionamento do reator e o processo de geração de energia elétrica, onde são enfatizadas as vantagens deste tipo de usina, os cuidados com o meio ambiente e com o lixo nuclear e a segurança da população da cidade. Em seguida, um funcionário se coloca à disposição para tirar dúvidas, explicando um pouco mais sobre os vídeos. Depois, os alunos são encaminhados para uma sala que possui imagens e a história da usina, desde a sua construção, e também uma maquete de um reator nuclear. Após o término na visitação no centro de informações, os alunos são levados para observar a réplica de uma sala de controle de um reator, onde os candidatos a operadores do reator fazem treinamento. A mesma funcionária acompanha os alunos para explicação de como se dá a formação de um operador do reator nuclear e, em seguida, a visita é finalizada.

\section{AULA 12}

subtema: Usinas Nucleares

Assunto: Acidente em Goiania (Césio 137)

Pré-requisitos. Não são necessários pré-requisitos para compreensão desta aula, pois se trata do relato de um acontecimento histórico.

Objetivos. Apresentar um documentário sobre o acidente ocorrido em Goiânia, no Brasil, com o Césio-137. Compreender as condições e os motivos que levaram ao acidente e suas consequências. Mostrar a importância da informação e conhecimento sobre a ciência e a tecnologia para a sociedade. Compreender que a radiação está presente em outros elementos químicos, além do urânio. Compreender que a tecnologia deve ser manipulada com cautela e bom-senso e que a segurança e o controle devem prevalecer sempre.

Desenvolvimento do tema: Toda a discussão será realizada em cima de um documentário sobre o acidente ocorrido em Goiânia, no Brasil, em setembro de 1987. 


\section{AULA 13}

Assunto: Radioatividade

Pré-requisitos. Será assumido que os alunos conhecem a tabela periódica e as características de alguns elementos, bem como compreendem a estrutura do átomo.

Objetivos. Compreender a natureza da radioatividade e saber diferenciá-la do Raio-X. Compreender que existem vários tipos de radiação. Conhecer a aplicação da radiação na medicina. Compreender os riscos que a exposição à radiação pode oferecer. Conhecer o histórico dos estudos com os elementos radioativos e os cientistas que realizaram esses estudos. Compreender o conceito de meia-vida e conhecer as características de alguns elementos radioativos.

Desenvolvimento do tema: A aula será apresentada em slides. Será apresentado o Raio-X e o um breve histórico de seu descobrimento, bem como sua natureza e utilidade. Em seguida serão apresentados alguns elementos radioativos e um breve histórico sobre o descobrimento destes. Serão diferenciadas as naturezas do Raio-X e das demais radiações nucleares. Será apresentada Marie Curie e seus trabalhos. Será explicada a origem da radiação, diferenciando as partículas alfa e beta e os raios gama. Será mostrado o espectro eletromagnético e a diferença entre as radiações que são prejudiciais e as que não são. Serão mostradas as utilidades da radiação para tratamentos médicos, bem como as conseqüências de seu mau uso. Será explicado o conceito de meia vida dos elementos radioativos, exemplificando com dados de alguns elementos.

\section{AULA 14}

subtema: Usinas Nucleares

Assunto: Vantagens e desvantagens das usinas nucleares

Pré-requisitos. É necessário que os alunos tenham participado das aulas 8 a 13.

Objetivos. Através de uma atividade em grupo, promover a discussão sobre vantagens e desvantagens, levando a uma tomada de decisão a favor ou contra as usinas nucleares e ao desenvolvimento de uma ação social responsável.

Desenvolvimento do tema: Na aula anterior, deverá ser solicitado aos alunos que formem grupos de 3 a 4 pessoas e se posicionem contra ou a favor das usinas nucleares, de modo que todos os integrantes do grupo estejam em consenso quanto à opinião. O grupo deverá, então, em casa, criar um vídeo, no qual defendam ou critiquem as usinas nucleares dando enfoque à Usina Nuclear de Angra dos Reis. Para criar o vídeo, poderão usar imagens, animações, outros vídeos e suas próprias gravações, usando a criatividade e os conhecimentos adquiridos nas aulas anteriores. Nesta aula, os vídeos serão exibidos e cada grupo irá defender suas ideias, promovendo um debate em sala de aula. Em seguida, o vídeo poderá ser publicado nas redes sociais para sensibilização da população local sobre o assunto. 